\title{
In vivo therapeutic potential of Inula racemosa in hepatic ischemia-reperfusion injury following orthotopic liver transplantation in male albino rats
}

Zhuoyi Wang ${ }^{1,2}$, Lei Geng ${ }^{1,2}$, Zhiyun Chen ${ }^{1,2}$, Bingyi Lin ${ }^{1,2}$, Mangli Zhang ${ }^{1,2}$ and Shusen Zheng ${ }^{1,2^{*}}$

\begin{abstract}
Hepatic ischemia-reperfusion (I/R) injury mainly occurs following hepatic resection and liver transplantation and cause severe liver damage, organ injuries, and dysfunction. Pro-inflammatory cytokines that promote injury are released when kupffer cell activates after getting induced by I/R. Repercussions of oxidative stress and cardiac function against isoproterenol based myocardial infarction are caused by flavonol glycosides which are found in high concentrations in Inula racemosa (Ir).The root was deemed to have analgesic and anti-inflammatory effects, and no report has been published about the liver-protective activity against hepatic I/R. Therefore, the present study was aimed to understand the therapeutic impact of Ir in hepatic I/R injury. Male albino, Wistar strain rats were used and were grouped into four total phenolic content, free radical scavenging activity and serum enzymes were determined. Histopathological and immunohistochemical analysis were also carried out. Inflammatory cytokines such as tumor necrosis factor-alpha (TNF-a) and interleukin (IL-6) and protein expression of p53, bax, and bcl-2 were determined. The administration of extracts of Ir significantly increased total phenolic and free radical scavenging activity. Altered cellular morphology, cytokines and aspartate aminotransferase (AST), alanine aminotransferase (ALT), alkaline phosphatase $(A L P)$, and lactate dehydrogenase (LDH) were returned to near normal level. IL-6 and TNF-a levels were reduced more than $25 \%$ following treatment. Also, the protein expression of p53, bax, and bcl-2 were also returned to near normal level. Taking all these data together, it is suggested that the extracts of Ir may be a potential therapeutic agent for providing several beneficial effects in hepatic I/R injury.
\end{abstract}

Keywords: Inula racemosa, p53, ALT, Cytokines, Antioxidant

\section{Introduction}

When after a period of ischemia blood supply returns to the tissue causing tissue abrasion is reperfusion injury (Grace 2005). During the ischemic period due to the absence of oxygen and essential nutrients a condition occurs, rather than restoration of oxidative damage and inflammation through oxidative stress is caused as a result of the restoration of circulation. Liver

\footnotetext{
*Correspondence: shusenzheng@hotmail.com

${ }^{2}$ Division of Hepatobiliary and Pancreatic Surgery, Department of Surgery, First Affiliated Hospital, School of Medicine, Zhejiang University, Zhejiang 310003, China

Full list of author information is available at the end of the article
}

ischemia-reperfusion (I/R) injury is well denoted as a notable reason for mortality and morbidity (Glantzounis et al. 2005). It often occurs in liver transplantation (Liu et al. 1991) and resections (Caldwell-Kenkel et al. 1991; Deschênes et al. 1998) where ischemic liver or anoxic injury takes place. It also occurs as a repercussion of hypoxia or insufficient perfusion occurring due to certain conditions that lower blood flow to the liver. Latter materialize in cardiogenic, hemorrhagic with fluid resuscitation (Yamakawa et al. 2000) in abdominal compartment syndromes (Okano et al. 2002) in cardiovascular and laparoscopic surgery (Glantzounis et al. 2001; Moore et al. 2005). 
Liver transplantation, $\mathrm{I} / \mathrm{R}$ injury is pertinent to the growth of primary graft dysfunction (occurrence in $10-25 \%$ of grafts) and primary graft non-function (an event in 5\% of grafts) (Clavien et al. 2007). High rates of mortality are observed in both conditions. I/R injury elevate the occurrence of graft rejection (Fellstrom et al. 1998). Transplantation or liver resection with steatotic livers is another area where $I / R$ injury affect. Some degree of liver steatosis has been observed in $25 \%$ of the western population (Selzner and Clavien 2001), the vast mass of TG inside the cytoplasm, ascribed to the effects of obesity, excess diabetes alcohol, and drugs.

Medicinal plants and phytochemicals have intensified because of potential chemotherapeutic values in animal diseases. The root of Inula racemosa (Ir) has been considered to exhibit cardio-protective effect and relieve ischemic pain (Manipuri et al. 2013). Sesquiterpenes, alloalantolactone, isoalantolactone, and alantolactone which are considered for therapeutic potential. Some glycosides, eudesmenes, germacranolides are also present in it. Ir should be considered for future studies as they offer new substitutes to the therapeutic options are very limited for liver diseases (Veteläinen et al. 2007; Kaplowitz 2000; Muthuviveganandavel et al. 2008; Olthoff et al. 2010; Gibson and Dudley 1984; Sylvia and Adam 1972). Several chemically defined molecules have been extracted from natural origins due to strong hepatoprotective activities epitomize an important source for effective liver protective agents. The need for this study exists on this basis.

\section{Materials and methods Chemicals}

Xylazine, ketamine hydrochloride, chloroform, $n$-hexane, dimethyl sulfoxide (DMSO), and spirit were obtained from Sigma-Aldrich (USA). Aspartate aminotransferase (AST), alanine aminotransferase (ALT), alkaline phosphatase (ALP), and lactate dehydrogenase (LDH) enzyme kits were obtained from Bio-Rad (UK). The p53, bax and bcl-2 monoclonal antibody, and HRP-conjugated goat anti-rabbit IgG were purchased from Sigma-Aldrich (St. Louis, MO 63178 USA).

\section{Preparation of plant extract}

Ir was obtained from National Research Institute for Sowa Rigpa (Amchi) Research Centre, Leh-Ladakh, India. Ir $(2 \mathrm{~kg})$ were cut into small pieces, shade dried for 7 days. A closed container was used in which Ir was taken and treated in $n$-hexane for about 2 days with infrequent shaking (Mohan and Gupta 2017). Marc was pressed after the n-hexane was strained off and kept for 4 days with infrequent shaking in a hydroalcoholic mixture.
Until the formation of brown colored paste, the solution was filtered and concentrated. Two liters of n-hexane and methanol was used.

Gas chromatography-mass spectrometry (GC/MS) analysis Ir extracts were analyzed using gas chromatographymass spectrometry (GC/MS, Thermo Fisher Scientific Korea Ltd. Seoul 06177, Korea). Compound identification was based on the retention time values and reported literature for authentic compounds (Kalachaveedu et al. 2017).

\section{Liquid chromatography-mass spectrometry (HPLC/MS) analysis}

Component analysis of Ir extracts was performed by liquid chromatography-mass spectrometry (HPLC/MS, Thermo Fisher Scientific Korea Ltd. Seoul 06177, Korea) analysis (Agilent 6500 Series) (So Hyun et al. 2017).

\section{Animals}

Healthy male albino Wistar strain rats were obtained from the animal house, Shangai, China, weighing (180$200 \mathrm{~g})$ was selected for the present study. Animals kept in polypropylene cages, at temperature $25 \pm 0.5^{\circ} \mathrm{C}$, relative humidity $60 \pm 5 \%$ and a photoperiod of $12 \mathrm{~h} /$ day. All the animals were handled according to internationally accepted ethical procedures. Ethical approval was obtained from the Ethics Committee of Wenzhou Medical University (Approval No. 201308807).

\section{Induction of hepatic $\mathrm{I} / \mathrm{R}$}

The foods were removed, and animals fasted before the experiment. Ketamine hydrochloride $(100 \mathrm{mg} / \mathrm{kg})$ and xylazine $(10 \mathrm{mg} / \mathrm{kg})$ were used to anesthetize animals. Ischemia was induced by clamping the hepatic portal triad. Bulldog clamp was used to clamp the hepatic portal train for 40 min which in turn produced Ischemia. Repercussion was generated through unclamping the triad for 40 min (Manipuri et al. 2013).

\section{Experimental group}

Animals were divided into four each containing six. Group I: sham, group II: control, group III: I/R + Ir $(100 \mathrm{mg} / \mathrm{kg})$ and group IV: I/R + Ir $(200 \mathrm{mg} / \mathrm{kg})$. The oral gauge was used for drug administration for the 15 consecutive days.

\section{Collection of blood and liver}

Blood was collected from all animals through cardiac puncture. Animals were sacrificed by decapitation, and liver tissue was surgically removed and place ice-cold saline and kept at $-20{ }^{\circ} \mathrm{C}$ for the further experiments. 


\section{Determination of total phenolic contents}

The total phenolic contents were determined with use of Folin-Ciocalteu method. Experimental data were expressed as caffeic acid equivalents per $\mathrm{mg}$ of dry extract weight (Faten et al. 2014). The total anthocyanin was measured with use of the $\mathrm{pH}$ differential method. Experimental data are expressed as $\mathrm{mg}$ of dry weight (Shoib and Shahid 2015).

\section{DPPH scavenging activity}

$\alpha, \alpha$-diphenyl- $\beta$-picrylhydrazyl (DPPH) reduction was measured by the standard method, and the experimental results are expressed as $\mu \mathrm{g}$ of extract dry weight (Cavin et al. 1998).

\section{ABTS scavenging activity}

2,2'-Azino-bis(3-ethylbenzothiazoline-6-sulphonic acid) (ABTS) scavenging activity was measured by the wellknown standard method, and the experimental data are expressed as mg of dry extract weight (Re et al. 1999).

\section{Ferric reducing antioxidant power (FRAP)}

The reducing ability of extract was determined with use of FRAP analysis, and it was determined by the standard method. Experimental data are expressed as $\mu \mathrm{mol}$ of extract dry weight (Benzie and Strain 1996).

\section{Determination of serum enzymes}

ALT, AST, ALP, and LDH were determined in the serum by using kit (Span Diagnostics Ltd., India) method (Muthuviveganandavel et al. 2008).

\section{Histopathological and biochemical assays}

Histopathological studies were conducted with sections (Kedee New, High Guality and Stable Rotary Microtome, Zhejiang Jinhua Kedi Instrumental Equipment Co., Ltd. Zhejiang, China) of liver fixed in formalin and staining was carried out with hydrated tissue sections in $5 \mu \mathrm{m}$ with Hematoxylin and Eosin ( $\mathrm{H} \& \mathrm{E})$. The sections were observed under a light microscope (Muthuviveganandavel et al. 2008).

\section{Determination of TNF- $\alpha$ and IL- 6 content}

Tumor necrosis factor-alpha (TNF- $\alpha$ ) and interleukin (IL-6) content were determined in the plasma. Enzyme-linked immune sorbent assay (ELISA) method was used to determine IL- 6 and TNF- $\alpha$ in the plasma. Briefly, IL- 6 and TNF- $\alpha$ present in the plasma to antiIL- 6 and anti-TNF- $\alpha$ monoclonal antibody adsorbed to the microwells. A biotin-conjugated monoclonal antiIL- 6 and anti-TNF- $\alpha$ antibody were incubated with IL-6 and TNF- $\alpha$ antibody. The unbound antibody has been removed through repeated washing with PBS. Then,
streptavidin-HRP was incubated with biotin-conjugated anti-IL- 6 and anti-TNF- $\alpha$, and substrate HRP was added to samples. The resultant colored product was measured at $450 \mathrm{~nm}$ (Afshari et al. 2005).

\section{Western blot analysis}

Cell homogenate was washed with PBS, and lysed with $10 \mathrm{mM}$ Tris- $\mathrm{HCl}$ (pH 7.5), $100 \mathrm{mM} \mathrm{NaCl}, 1 \% \mathrm{NP}-40$, $50 \mathrm{mM}$ NaF, $2 \mathrm{mM}$ EDTA (pH 8.0), $10 \mu \mathrm{g} / \mathrm{mL}$ leupeptin, $1 \mathrm{mM}$ PMSF and $10 \mu \mathrm{g} / \mathrm{mL}$ aprotinin. The protein which is present in the lysate was run on SDS-PAGE. PVDF membrane was used for transferring in the SDS-PAGE. TBST was used for the non-specific blocking proteins. The membrane probed for $12 \mathrm{~h}$ with an antibody against p53, Bax, and Bcl-2. Membranes were washed twice with TBST and incubated with HRP-conjugated goat antirabbit IgG (St. Louis, MO 63178 USA) for $60 \mathrm{~min}$. The protein levels of $\mathrm{p} 53$, bax, and bcl-2 were determined by using enhanced chemiluminescence method (Muthuraman et al. 2014).

\section{Immunohistochemical analysis}

Liver tissue was surgically removed from the rat animals following decapitation and rinsed in ice-cold normal saline. Paraformaldehyde was used for fixation of liver and dehydrated with ethanol. Then, tissues were embedded in paraffin wax and dewaxed and rehydrated before sectioning. Sections were made and incubated with mouse anti-p53, anti-bax and anti-bcl-2 (1:300, Abcam, USA) for overnight at $4{ }^{\circ} \mathrm{C}$. After repeated washing with PBS, sections were incubated with HRP-conjugated secondary antibody at $37^{\circ} \mathrm{C}$ for $60 \mathrm{~min}$. Sections were counterstained with hematoxylin (Muthuraman and Srikumar 2009).

\section{Statistical analysis}

All the experimental values are expressed as a mean \pm standard error of the mean (SEM). The control and treated groups were compared using ANOVA (SPSS 15, Chicago, IL, USA). Furthermore, all the groups are compared using Student " $t$ " test. A P $<0.05$ was considered statistically significant.

\section{Results}

The GC-MS analysis was used to get preliminary data on the composition of Ir extracts in the present study. The polarity of the solvents could affect the efficiency of extraction and activity of obtained compounds in the extracts. Ethyl acetate, ethanol, methanol, acetone, and water are most generally solvents for extraction. The compound obtained in the Ir extract is given in Table 1. HPLC/MS provides cost-effective tool for the identification of phenolic compounds. The chemical constituents 
Table 1 Retention time (Rt) of compounds identified in the extract of Ir

\begin{tabular}{|c|c|c|c|}
\hline No & Constituent & Retention time (min) & Identification \\
\hline 1 & 2-Methoxyethanol & 15.241 & Ref, Lib \\
\hline 2 & Nonane, 3-methyl-5-propyl-methyl benzoate & 16.013 & Ref, Lib \\
\hline 3 & Alpha-muurolene & 19.435 & Ref, Lib \\
\hline 4 & 2-Phenyl-2-propanol & 21.618 & Ref, Lib \\
\hline 5 & Benzene, 1-(1,5-dimethyl-4-hexenyl)-4-methyl-1-butanol & 22.624 & Ref, Lib \\
\hline 6 & Hexanal dimethyl acetal & 23.958 & Ref, Lib \\
\hline 7 & 2-Methoxyethanol & 24.451 & Ref, Lib \\
\hline 8 & 1-Pentanol & 25.223 & Ref, Lib \\
\hline 9 & Propionitrile, 2-(3-fluorophenylhydrazono)-3-imino-3-(4-morpholyl)- tetradecane & 36.521 & Ref, Lib \\
\hline 10 & 1-Hexanol, 2-ethyl & 43.536 & Ref, Lib \\
\hline 11 & 2-Propenoic acid, 2-methyl-cyclohexyl ester & 44.321 & Ref, Lib \\
\hline 12 & Beta elemene & 51.612 & Ref, Lib \\
\hline 13 & Benzaldehyde & 46.622 & Ref, Lib \\
\hline 14 & Nonane, 3-Methyl-5-propylnonane & 50.776 & Ref, Lib \\
\hline 15 & Methyl benzoate & 53.745 & Ref, Lib \\
\hline 16 & Benzoic acid & 52.206 & Ref, Lib \\
\hline 17 & Acetophenone & 56.414 & Ref, Lib \\
\hline 18 & Alpha-amorphene & 56.494 & Ref, Lib \\
\hline 19 & Alpha-muurolene & 55.394 & Ref, Lib \\
\hline 20 & 2-Phenyl-2-propanol & 58.333 & Ref, Lib \\
\hline 21 & Alpha-selinene & 59.103 & Ref, Lib \\
\hline 22 & Beta-selinene & 61.111 & Ref, Lib \\
\hline 23 & Azulene & 62.495 & Ref, Lib \\
\hline
\end{tabular}

GC/MS comparison with GC/MS standard, Ref comparison with GC and MS literature values

are expressed on the dry weight basis. The compounds obtained in the Ir extracts are given in Table 2.

The total phenolic and anthocyanins contents were determined in the extract of Ir. Total phenolic and

\section{Table 2 The compounds obtained in the Ir extracts}

\begin{tabular}{lll}
\hline S.No & Name of the constituents & Quantity $\mathbf{( m g / 1 0 0 ~ g ) ~}$ \\
\hline 1 & $\begin{array}{l}\text { 3,5-Dihydroxybenzoic acid-O-glucosyl- } \\
\text { xyloside }\end{array}$ & 13.9 \\
2 & Chlorogenic acid & 33.2 \\
3 & Catechin gallate & 22.5 \\
4 & Caffeic acid & 93.72 \\
5 & Alantolactone & 42.42 \\
6 & Kaempherol-7-O-dipentoside & 42.9 \\
7 & Galloyl-caffeoylhexose & 11.9 \\
8 & Quercetin-3-O-beta-glucopyranoside & 51.1 \\
9 & Dicaffeoyl quinic acid & 70.3 \\
10 & 9-O-beta-D-glucopyranosyl-9-hydroxy- & 19.2 \\
& thymol & 29.8 \\
11 & 5-O-feruloylquinic acid & 13.2 \\
12 & Dihydrocaffeic acid derivative & 22.7 \\
13 & Epicatechin & 1.6 \\
\hline 14 & 6"-O-malonyl genistein & \\
\hline
\end{tabular}

anthocyanins contents were $48.26 \mu \mathrm{g} / \mathrm{mg}$ and $39.5 \mu \mathrm{mol} /$ mg of dry weight respectively (Fig. 1a). DPPH scavenging activity was 38.6 and $15.4 \mu \mathrm{g} / \mathrm{mg}$ of dry weight in the sham and control group respectively. Treatment of rats with extracts of Ir significantly improved DPPH scavenging activity. DPPH scavenging activity was 21.2 and $31.5 \mu \mathrm{g} / \mathrm{mg}$ of dry weight in the group III and IV respectively (Fig. $1 \mathrm{~b}, \mathrm{P}<0.05$ ). ABTS scavenging activity was 89.3 and $39.89 \mu \mathrm{g} / \mathrm{mg}$ of dry weight in the sham and control group respectively. Treatment of rats with extracts of Ir significantly improved ABTS scavenging activity to 49.5 and $76.48 \mu \mathrm{g} / \mathrm{mg}$ of dry weight in the group III and group IV respectively (Fig. 1c, P < 0.05). Ferric reducing antioxidant power was 266.6 and $105.34 \mu \mathrm{mol} / \mathrm{mg}$ of dry weight in the sham and control group respectively. Treatment of rats with extracts of Ir significantly improved FRAP to 149.61 and $229.81 \mu \mathrm{mol} / \mathrm{mg}$ of dry weight in the group III and group IV respectively (Fig. 1d, P < 0.05).

AST, ALT, ALP and LDH levels were reduced following treatment compared to the control. These serum enzymes were significantly reduced at higher concentration of Ir in this study. Treatment showed increased AST, ALT, ALP and LDH levels compared to the standard control, but lesser than model control which indicates that treatment had a significant effect on the 

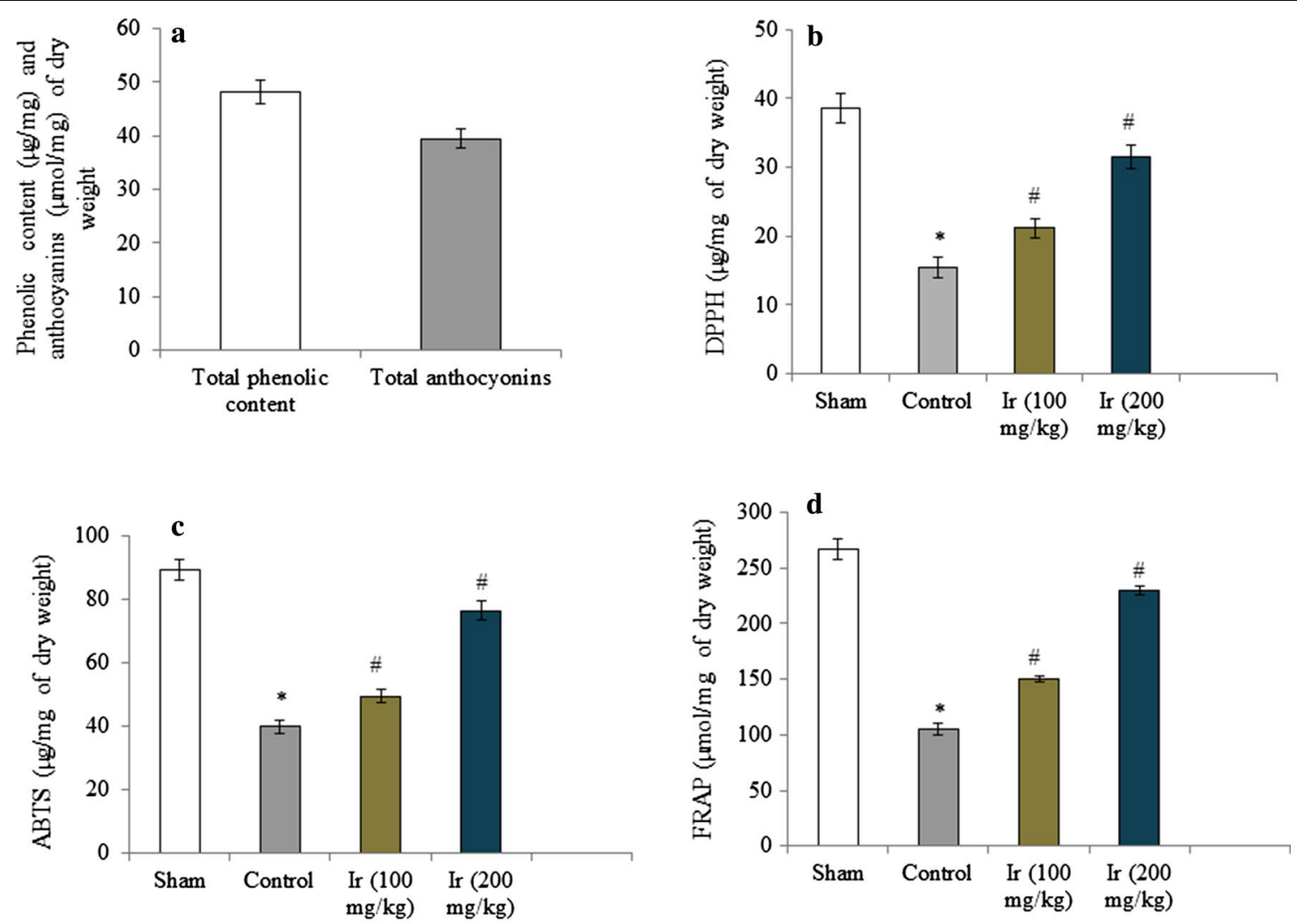

*P $<0.05 \&$ \& $<<0.05$

Fig. 1 Total phenolic and anthocyanins content in the extract of $\operatorname{Ir}(\mathbf{a})$. DPPH activity in control and treated rats (b). ABTS activity in control and treated rats (c). FRAP activity in control and treated rats $(\mathbf{d}) . \mathrm{N}=6,{ }^{*} P<0.05$ vs. control group, ${ }^{\sharp} P<0.05$ vs. treated groups

reduction of these enzymes (Figs. 2, 3, 4, 5, P < 0.05). No pathology was found in the sham group. Liver histology showed the normal cellular architecture, and there was no congestion and necrosis. Liver cells were arranged in the cord. Several portal tracks were observed in the liver histology. Dilated sinusoids and veins were seen, as well as inflammation and necrosis was found in the control group (Fig. 6). However, the Ir treatment significantly reduced these abnormalities compared.

IL- 6 and TNF- $\alpha$ levels were determined to understand the effect of an extract of Ir on inflammation. IL- 6 and TNF- $\alpha$ levels were significantly increased 284.36 and $397.85 \%$ in the control rats compared to the sham. However, the treatment of extracts of Ir significantly reduced the IL- 6 level to 26.26 and $54.25 \%$ in group III and group IV respectively. The TNF- $\alpha$ concentration was reduced to 47.08 and $67.17 \%$ in group III and group IV respectively (Fig. 7, P < 0.05). Reduced level of cytokines revealed that extract of Ir possesses hepato-protective activity in hepatic ischemic/reperfusion injury in rats.

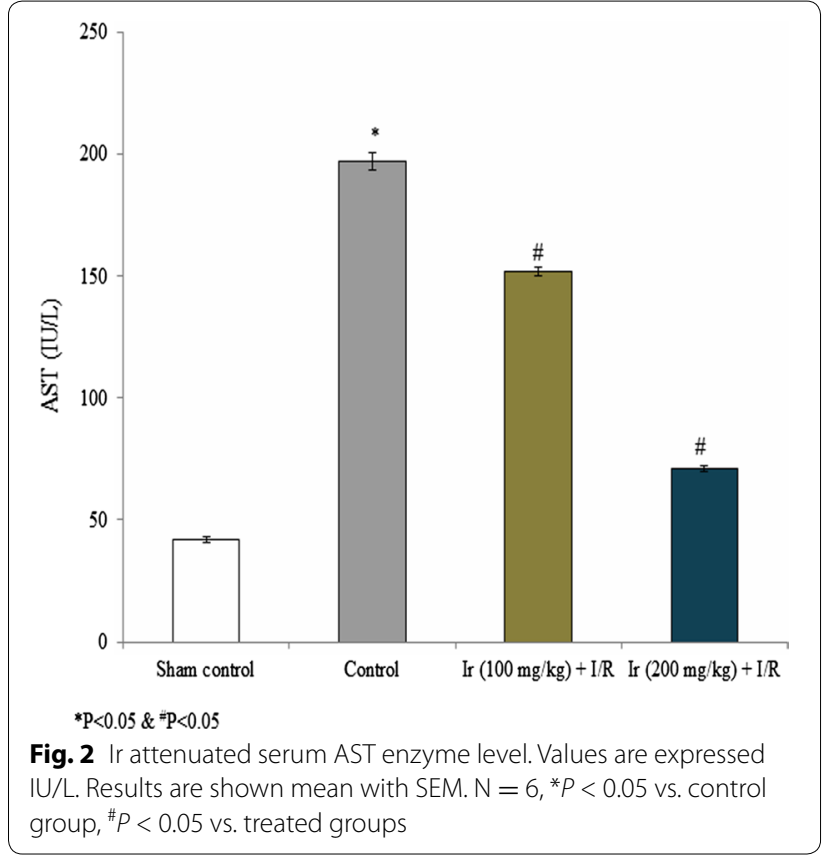




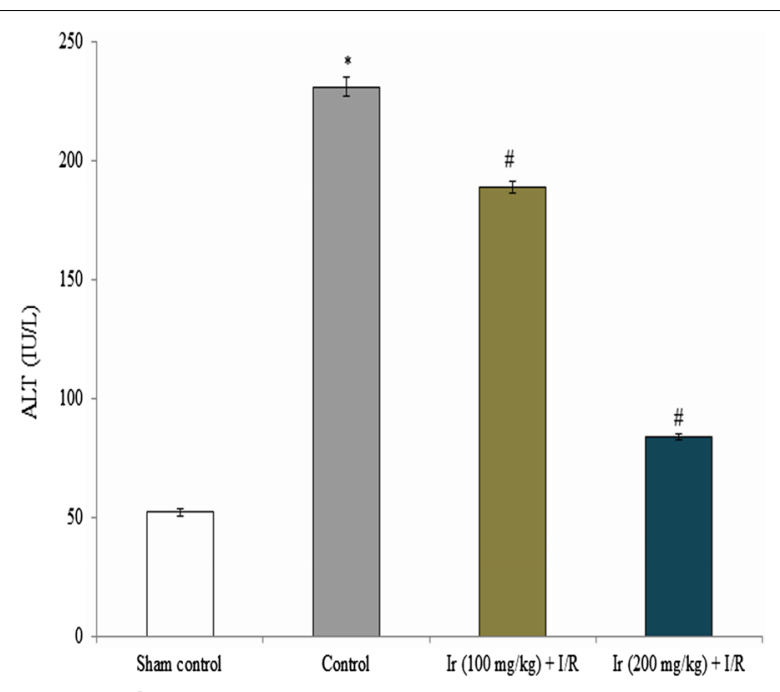

${ }^{*} \mathrm{P}<0.05 \& * \mathrm{P}<0.05$

Fig. 3 Ir attenuated serum ALT enzyme level. Values are expressed IU/L. Results are shown mean with SEM. $N=6,{ }^{*} P<0.05$ vs. control group, ${ }^{\#} P<0.05$ vs. treated groups

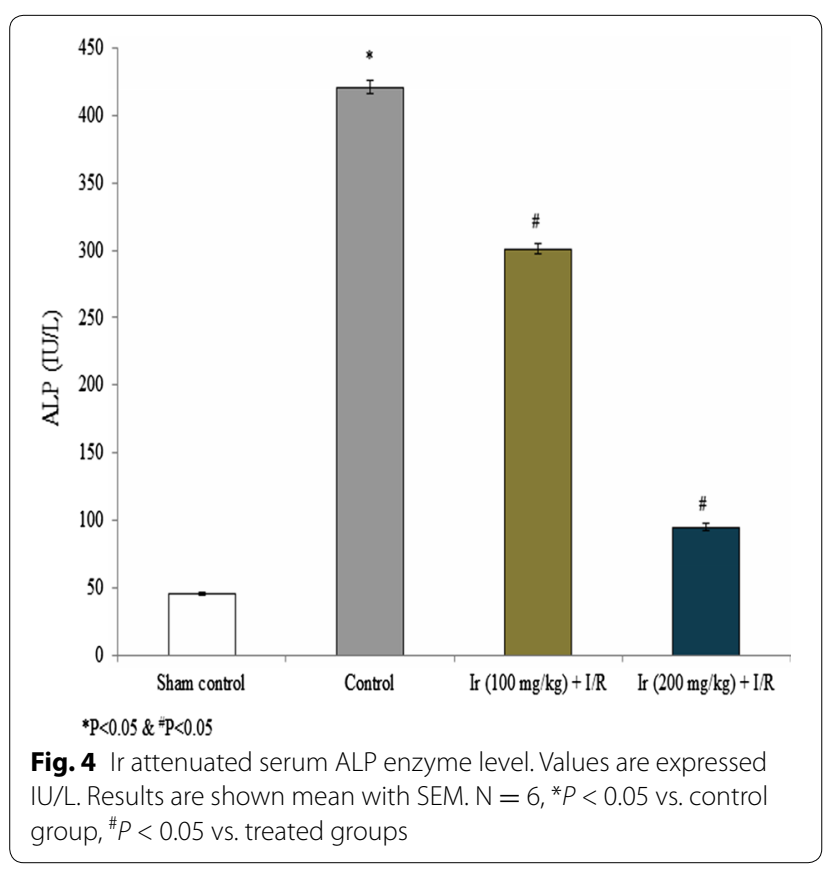

To understand the effect of Ir on protein expression of p54, bax and bcl-2, we carried out western blot analysis. Protein expression of p54, bax and bcl-2 were significantly altered compared to the control. The bcl-2 protein expression was reduced to 0.54 fold in control

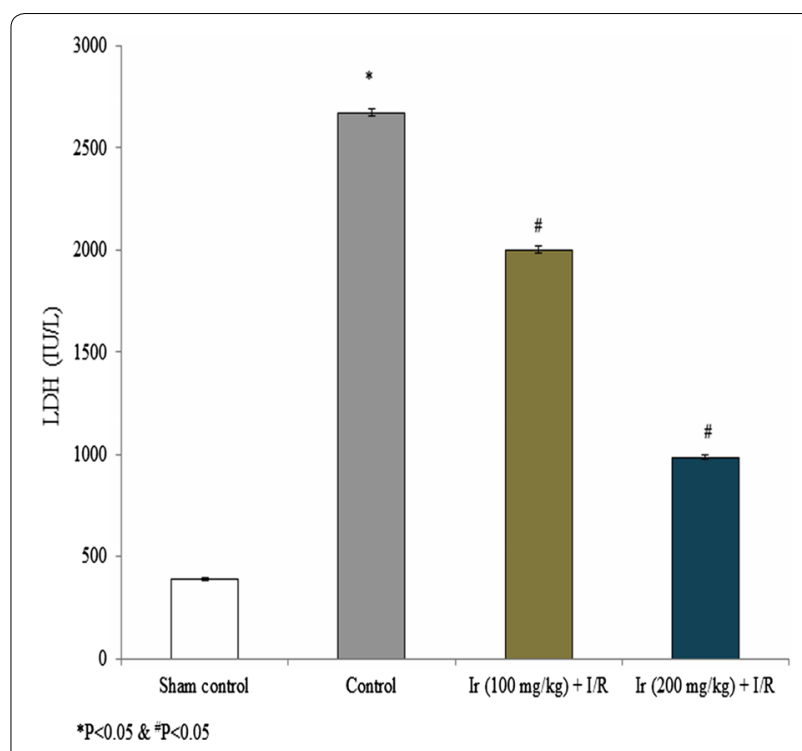

Fig. 5 Ir attenuated serum LDH enzyme level. Values are expressed IU/L. Results are shown mean with SEM. $N=6,{ }^{*} P<0.05$ vs. control group, ${ }^{\#} P<0.05$ vs. treated groups

compared to the sham control. Ir treatment significantly increased bcl- 2 expression 0.45 and 0.87 folds in group III and group IV respectively. The p53 protein expression was reduced to 0.08 -fold in control compared to the sham control. Ir treatment significantly reduced p53 expression 0.34- and 0.47-folds in group III and group IV respectively. The bax protein expression was reduced to 0.04 -fold in control compared to the sham control. Ir treatment significantly reduced bax expression 0.22 - and 0.41 -folds in group III and group IV respectively (Fig. $8, \mathrm{P}<0.05$ ). Renormalization of cancer apoptotic gene expression revealed that the extract of Ir possesses hepato-protective activity in hepatic ischemic/reperfusion injury in rats.

Immunohistochemistry revealed the effect of Ir on p53, bax and bcl-2 expression. The p53, bax and bcl-2 protein expression were reduced in control compared to the sham control. Ir treatment significantly reduced the p53 and bax expression compared to the control, whereas bcl-2 expression was dramatically increased compared to the control. The effect was found in a dose-dependent manner (Fig. 9).

\section{Discussion}

The GC-MS and HPLC/MS analysis was used to get preliminary data on the composition of Ir extracts in the present study. The presence of alkaloids, 


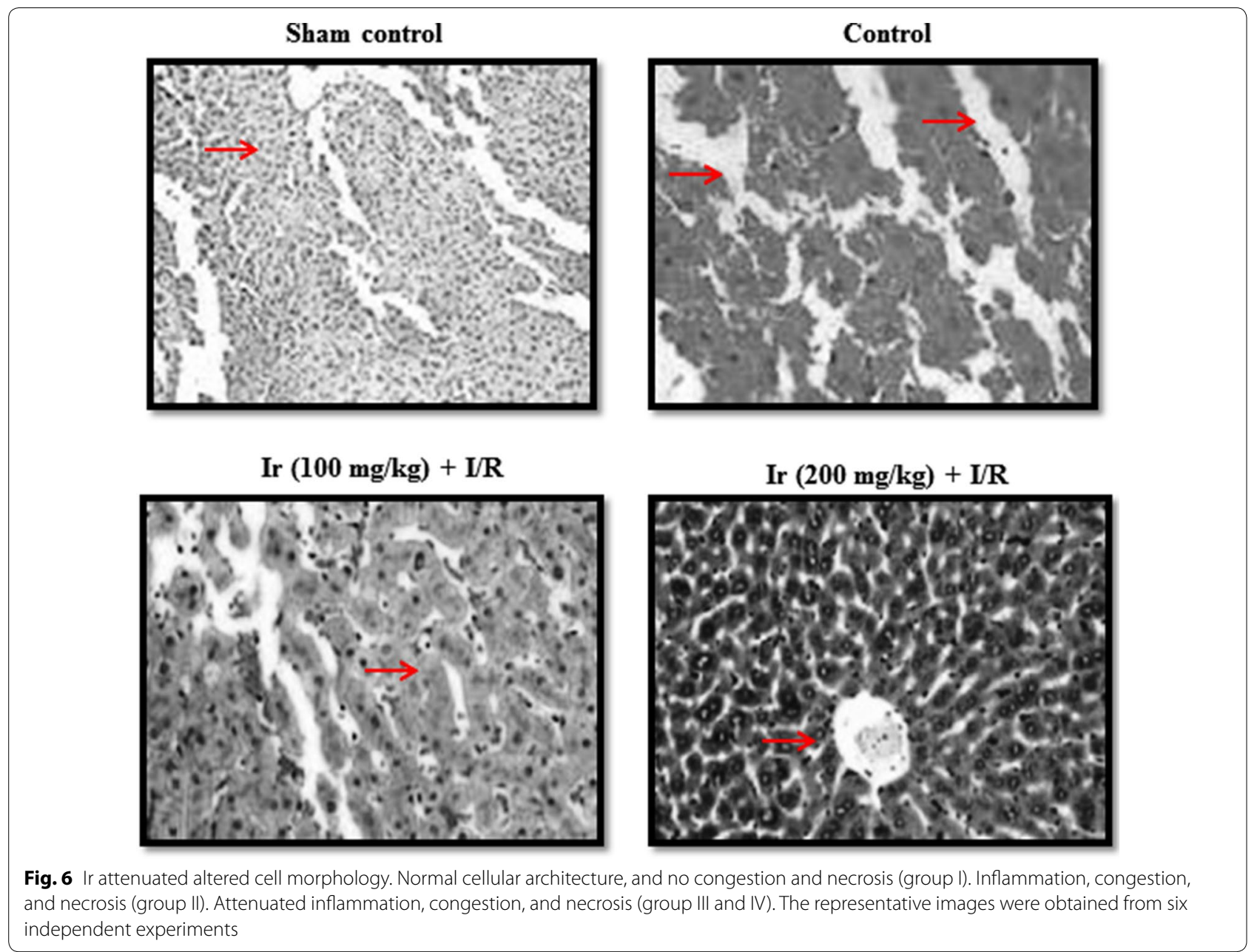

phenols and flavonoids in the extract of Ir may induce directly or indirectly to neutralize the oxidants and activation of free radical scavenging system (Dinkova-Kostova 2008). Zheng and Wang (2001) have reported that the degree of flavonoid and polyphenol abundance contains positive correlation to its free radical scavenging and antioxidant potential. Our results agree with findings of Mohan and Gupta (2017) who have stated that the right antioxidant activity of extracts of Ir in ABTS and FRAP assays. Our results agreed with findings of Manipuri et al. (2013) who have reported that the reduced level of serum hepatic enzymes and renormalization of altered cellular morphology following treatment of Ir in hepatic I/R injury in rats.

To understand the effect of Ir on protein expression of p54, bax and bcl-2, we carried out western blot analysis. Protein expression of p54, bax and bcl-2 were

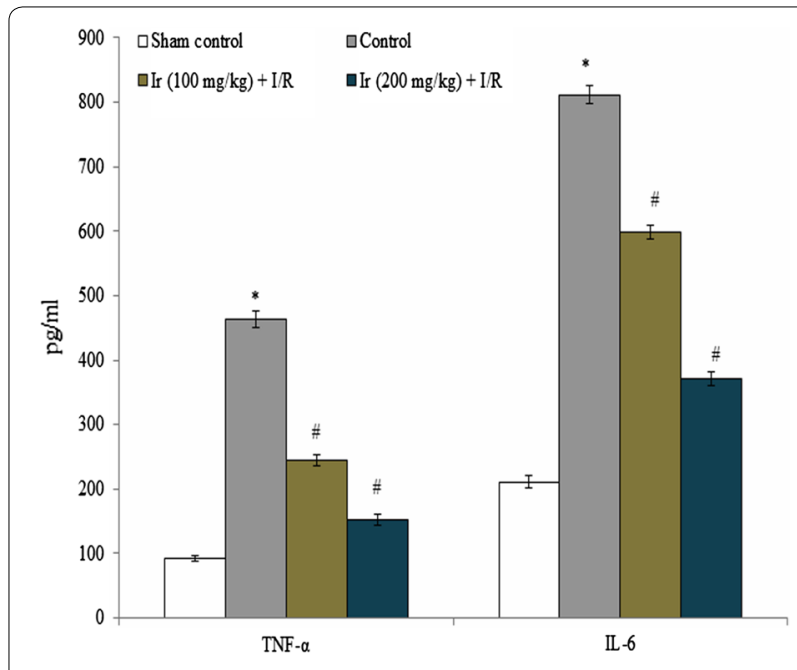

${ }^{*} \mathrm{P}<0.05 \& * \mathrm{P}<0.05$

Fig. 7 Ir attenuated serum IL-6 and TNF-a level. Values are expressed as $\mathrm{pg} / \mathrm{mL}$. The results are expressed as $+\mathrm{SEM}, \mathrm{N}=6,{ }^{*} P<0.05 \mathrm{vs}$. control group, ${ }^{\#} P<0.05$ vs. treated group 


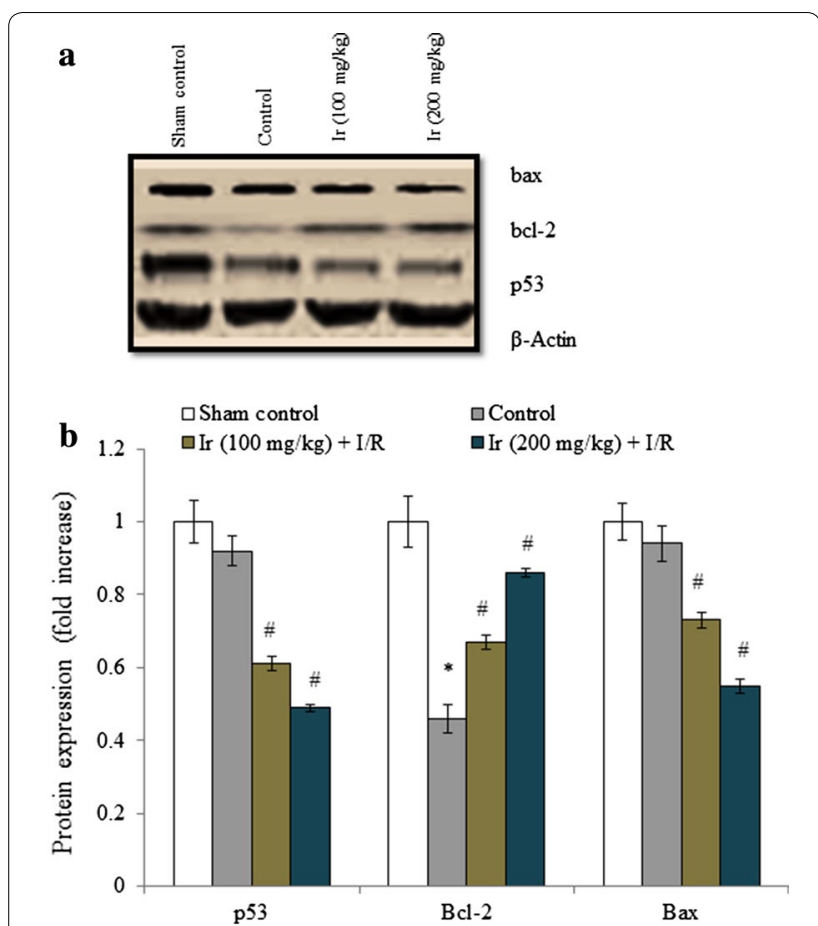

$* \mathrm{P}<0.05 \&$ \& $\mathrm{P}<0.05$

Fig. 8 The effect of Ir on the protein expression of p53, bcl-2 and bax. The western blot (a) and presentative images of p53, bcl-2 and bax (b). The results are expressed as $+\mathrm{SEM}, \mathrm{N}=6,{ }^{*} P<0.05 \mathrm{vs}$. control group, ${ }^{\#} P<0.05$ vs. treated groups significantly altered compared to the control. Renormalization of cancer apoptotic gene expression revealed that the extract of Ir possesses hepato-protective activity in hepatic ischemic/reperfusion injury in rats. Immunohistochemistry revealed the effect of Ir on p53, bax and bcl-2 expression. The $\mathrm{p} 53$, bax and bcl-2 protein expression were reduced in control compared to the sham control. Ir treatment significantly reduced the p53 and bax expression compared to the control, whereas bcl-2 expression was dramatically increased compared to the control. The effect was found in a dose-dependent manner. The medicinal property of Ir has been extensively studied in the ayurvedic system in rodents and human models (Miller 1998). Cardioprotective effect of Ir has been reported against isoproterenol-induced myocardial infarction (Ojha et al. 2011).

In summary, the administration of extracts of Ir significantly increased total phenolic content and free radical scavenging activity. Altered cellular morphology, cytokines and AST, ALT, ALP, and LDH were returned to near normal level. Also, the protein expression of $\mathrm{p} 53$, bax, and bcl-2 were also returned to near normal level. Taking all these data together, it is suggested that the extracts of Ir may be a potential therapeutic agent for providing several beneficial effects in hepatic $I / R$ injury following orthotopic liver transplantation.

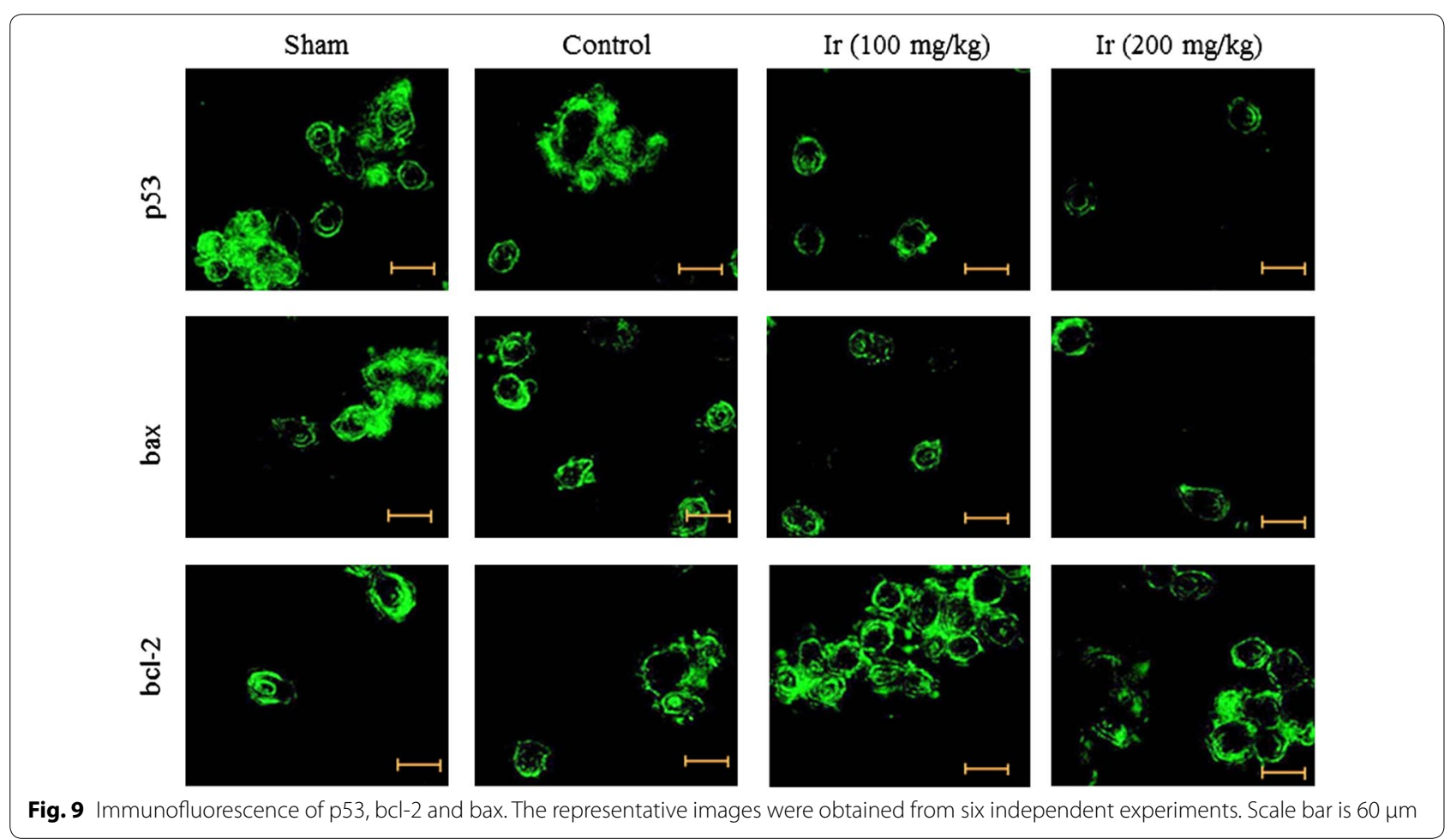




\section{Abbreviations}

I/R: ischemia-reperfusion (I/R); Ir: Inula racemosa; AST: aspartate aminotransferase; ALT: alanine aminotransferase; ALP: alkaline phosphatase; LDH: lactate dehydrogenase; DMSO: dimethyl sulfoxide; FRAP: ferric reducing antioxidant power; DPPH: a, a-diphenyl- $\beta$-picrylhydrazyl; ABTS: 2,2'-azino-bis(3-ethylbenzothiazoline-6-sulphonic acid); TNF-a: tumor necrosis factor-alpha; IL6: interleukin (IL-6); ELISA: enzyme-linked immune sorbent assay; PVDF: polyvinyl difluoride; SEM: standard error of the mean.

\section{Authors' contributions}

ZW and $L G$ performed experiments. $\mathrm{XL}, \mathrm{ZC}$ and $\mathrm{BL}$ interpreted data and carried out analysis. MZ and SZprepared manuscript. All authors read and approved the final manuscript.

\section{Author details}

${ }^{1}$ Key Laboratory of Combined Multi-organ Transplantation, Ministry of Public Health, Key Laboratory of Organ Transplantation, Zhejiang 310003, China. ${ }^{2}$ Division of Hepatobiliary and Pancreatic Surgery, Department of Surgery, First Affiliated Hospital, School of Medicine, Zhejiang University, Zhejiang 310003, China

\section{Acknowledgements}

Not applicable.

\section{Competing interests}

The authors declare that they have no competing interests.

\section{Availability of data and materials}

Data will not be shared now and will be shared in future after completing full research on it.

\section{Consent for publication}

Not applicable.

\section{Ethics approval and consent to participate}

All the animals were handled according to internationally accepted ethical procedures. Ethical approval was obtained from the Ethics Committee of Wenzhou Medical University (Approval No. 201308807).

\section{Funding}

Not applicable.

\section{Publisher's Note}

Springer Nature remains neutral with regard to jurisdictional claims in published maps and institutional affiliations.

Received: 14 October 2017 Accepted: 11 November 2017

Published online: 22 November 2017

\section{References}

Afshari JT, Ghomian N, Shameli A, Shakeri MT, Fahmidehkar MA, Mahajer E, Khoshnavaz E, Emadzadeh M (2005) Determination of interleukin-6 and tumor necrosis factor-alpha concentrations in Iranian-Khorasanian patients with preeclampsia. BMC Pregnancy Childbirth 5:14

Benzie IFF, Strain JJ (1996) The ferric reducing ability of plasma (FRAP) as a measure of "antioxidant power": the FRAP assay. Anal Biochem 239:70-76

Caldwell-Kenkel JC, Currin RT, Tanaka Y, Thurman RG, Lemasters JJ (1991) Kupffer cell activation and endothelial cell damage after storage of rat livers: effects of reperfusion. Hepatology 13:83-95

Cavin A, Hostettmann K, Dyatmyko W, Potterat O (1998) Antioxidant and lipophilic constituents of Tinospora crispa. Planta Med 64:393-396

Clavien PA, Harvey PRC, Sanabria JR, Cywes R, Levy GA (2007) Lymphocyte adherence in the reperfused rat liver: mechanisms and effects. Hepatology 17:131-142

Deschênes M, Belle SH, Krom RAF, Zetterman RK, Lake JR (1998) Early allograft dysfunction after liver transplantation: a definition and predictors of outcome. Transplantation 66:302-310
Dinkova-Kostova AT (2008) Phytochemicals as protectors against ultraviolet radiation: versatility of effects and mechanisms. Planta Med 74:1548-1559

Faten M, Hanen F, Riadh K, Chedly A (2014) Total phenolic, flavonoid and tannin contents and antioxidant and antimicrobial activities of organic extracts of shoots of the plant Limonium delicatulum. J Taibah Univ Sci 8:216-224

Fellstrom B, Akuyrek LM, Backman U, Larsson E, Melin J (1998) Post ischemic reperfusion injury and allograft arteriosclerosis. Transplant Proc 30:4278-4280

Gibson PR, Dudley FJ (1984) Ischemic hepatitis: clinical features, diagnosis, and prognosis. Aust NZ J Med 14:822-825

Glantzounis G, Tselepis A, Tambaki A, Trikalinos T, Manataki A (2001) Laparoscopic surgery-induced changes in oxidative stress markers in human plasma. Surg Endosc 15:1315-1319

Glantzounis GK, Salacinski HJ, Yang W, Davidson BR, Seifalian AM (2005) The contemporary role of antioxidant therapy in attenuating liver ischemiareperfusion injury: a review. Liver Transplant 11:1031-1047

Grace P (2005) Ischemia-reperfusion injury. Br J Surg 81:637-647

Kalachaveedu M, Raghavan D, Telapolu S, Kuruvilla S, Kedike B (2017) Phytoestrogenic effect of Inula racemosa Hook $\mathrm{f}$ - a cardioprotective root drug in traditional medicine. J Ethnopharmacol 8:408-416

Kaplowitz N (2000) Mechanisms of liver cell injury. J Hepatol 32:39-47

Liu DL, Jeppsson B, Hakansson CH, Odselius R (1991) Multiple-system organ damage resulting from prolonged hepatic inflow interruption: electron microscopic findings. Arch Surg 131:442

Manipuri P, Indala R, Jagaralmudi A, Ramesh Kumar K (2013) Hepatoprotective effect of Inula racemosa on hepatic ischemia/reperfusion induced injury in rats. J Bioanal Biomed 5:022-027

Miller AL (1998) Botanical influences on cardiovascular disease. Altern. Med. Rev. J. Clin. Ther 3:422-443

Mohan S, Gupta D (2017) Phytochemical analysis and differential in vitro cytotoxicity assessment of root extracts of Inula racemosa. Biomed Pharmacother 89:781-795

Moore EE, Moore FA, Harken AH, Johnson JL, Ciesla D (2005) The two-event construct of post injury multiple organ failures. Shock 24:71-74

Muthuraman P, Srikumar K (2009) A comparative study on the effect of homobrassinolide and gibberellic acid on lipid peroxidation and antioxidant status in normal and diabetic rats. J Enzyme Inhib Med Chem 24:1122-1127

Muthuraman P, Ramkumar K, Kim DH (2014) Analysis of the dose-dependent effect of zinc oxide nanoparticles on the oxidative stress and antioxidant enzyme activity in adipocytes. Appl Biochem Biotechnol 174:2851-2863

Muthuviveganandavel V, Muthuraman P, Muthu S, Srikumar K (2008) Effect of cypermethrin on serum enzymes. Pestic Biochem Physiol 26:561-569

Ojha S, Bharti S, Sharma AK, Rani N, Bhatia J, Kumari S, Arya DS (2011) Effect of Inula racemosa root extract on cardiac function and oxidative stress against isoproterenol-induced myocardial infarction. Indian J Biochem Biophys 48:22-28

Okano N, Miyoshi S, Owada R, Fujita N, Kadoi Y (2002) Impairment of hepatosplanchnic oxygenation and increase of serum hyaluronate during normothermic and mild hypothermic cardiopulmonary bypass. Anesth Analg 95:278-286

Olthoff KM, Kulik L, Samstein B, Kaminski M, Abecassis M, Emond J, Shaked JA, Christie JD (2010) Validation of a current definition of early allograft dysfunction in liver transplant recipients and analysis of risk factors. Liver Transplant 16:43-49

Re R, Pellegrini N, Proteggente A, Pannala A, Yang M, Rice-Evans C (1999) Antioxidant activity applying an improved ABTS radical cation decolorization assay. Free Radic Biol Med 26:1231-1237

Selzner M, Clavien PA (2001) Fatty liver in liver transplantation and surgery. Semin Liver Dis 21:105-114

Shoib AB, Shahid AM (2015) Determination of total phenolic and flavonoid content, antimicrobial and antioxidant activity of a root extract of Arisaema jacquemontii Blume. J Taibah Univ Sci 9:449-454

So Hyun M, Bhupendra M, Kim DH, Muthuraman P (2017) Antioxidant and anticancer potential of bioactive compounds following UV-C lightinduced plant cambium meristematic cell cultures. Ind Crops Prod 109:762-772

Sylvia MW, Adam L (1972) Serum enzyme levels in diagnosis of postoperative myocardial infarction. Br Med J 23:733-735 
Veteläinen R, van Vliet A, Gouma DJ, van Gulik TM (2007) Steatosis as a risk factor in liver surgery. Ann Surg 245:20-30

Yamakawa Y, Takano M, Patel M, Tien N, Takada T (2000) Interaction of platelet activating factor, reactive oxygen species generated by xanthine oxidase, and leukocytes in the generation of hepatic injury after shock/resuscitation. Ann Surg 231:387

Zheng W, Wang SY (2001) Antioxidant activity and phenolic compounds in selected herbs. J Agric Food Chem 49:5165-5170

\section{Submit your manuscript to a SpringerOpen ${ }^{\circ}$ journal and benefit from:}

- Convenient online submission

- Rigorous peer review

- Open access: articles freely available online

- High visibility within the field

- Retaining the copyright to your article

Submit your next manuscript at $\boldsymbol{\nabla}$ springeropen.com 